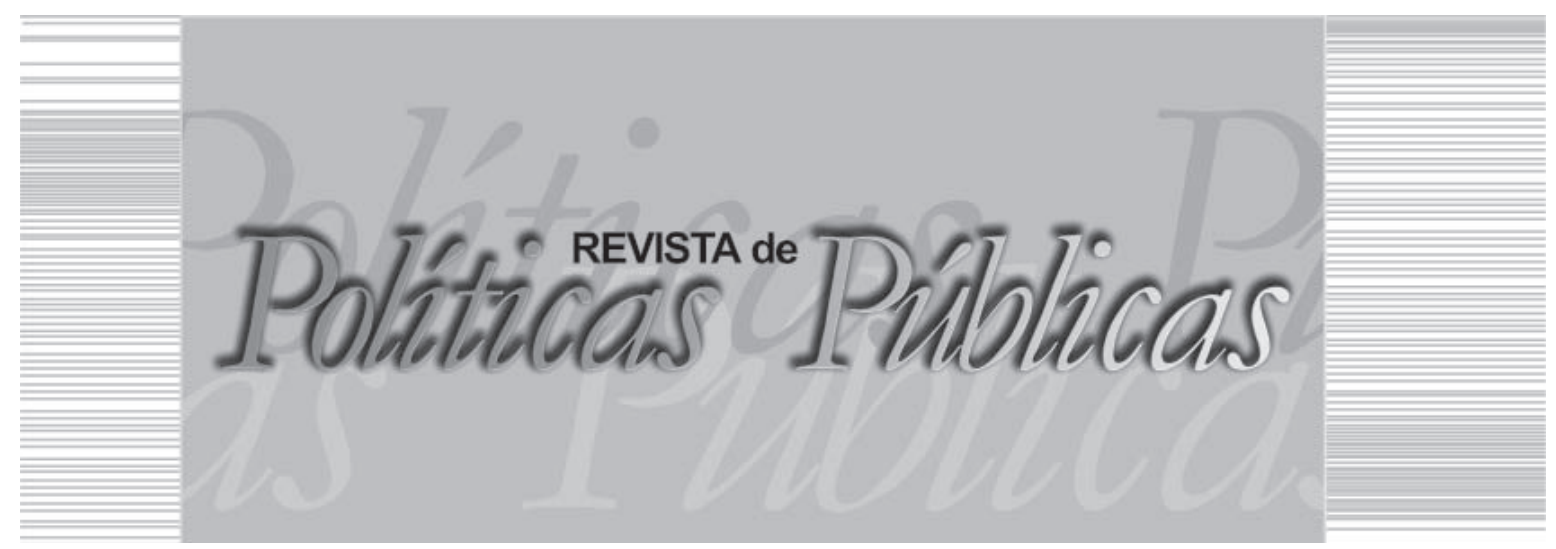

\title{
SEGURIDADE SOCIAL, MÍNIMO EXISTENCIAL E ATIVISMO JUDICIAL
}

Emerson Affonso da Costa Moura ${ }^{1}$ Universidade Federal de Juiz de Fora (UFJF)

\section{Resumo}

Os limites do ativismo judicial na promoção do mínimo existencial diante do papel exercido pela seguridade social na garantia da adjudicação das prestações necessárias para a satisfação dos direitos sociais é o tema posto em debate. Para tanto de início analisa-se os direitos sociais de forma a determinar o grau de sua exigibilidade. Após, verifica-se o papel do ativismo judicial na garantia da concretização de tais direitos fundamentais pela via jurisdicional. Por fim, confronta-se o papel da Seguridade Social na realização do mínimo existencial de forma a delimitar limites à atuação do Poder Judiciário.

Palavras-chaves: Direitos Sociais, seguridade social, mínimo existencial, ativismo judicial.

\section{SOCIAL SECURITY, EXISTENTIAL MINIMUM AND JUDICIAL ACTIVISM}

\begin{abstract}
The limits of judicial activism in promoting existential minimum on the role played by social security in securing the award of benefits necessary for the satisfaction of social rights is the theme put into discussion. Therefore early analyzes social rights in order to determine the extent of their liability. After,

\footnotetext{
Advogado. Doutorando em Direito pela Universidade do Estado do Rio de Janeiro (UERJ). Professor Assistente no Campus Governador Valadares da Universidade Federal de Juiz de Fora (UFJF). E-mail: emersonacmoura@yahoo.com.br | Universidade Federal de Juiz de Fora - UFJF | Campus Governador Valadares - Av. Dr. Raimundo Monteiros Rezende, 330 Sala da Secretaria da UFJF Centro (Prédio Pitágoras) | CEP: 35012-140
} 
there is the role of judicial activism in ensuring the realization of these fundamental rights by judicial action. Finally, confronted the role of Social Security in the realization of the existential minimum in order to define limits to the work of the judiciary.

Key words: Social rights, social security, existential minimum, judicial activism.

\section{INTRODUÇÃO}

O constitucionalismo contemporâneo tem exercido um papel importante na proteção e promoção dos direitos fundamentais, em especial, dos direitos sociais uma vez que o reconhecimento da supremacia formal e axiológica da Constituição Federal e da exequibilidade plena destes direitos tem se admitido a sua exigibilidade perante os poderes públicos.

Com a ascensão político-institucional e o amplo processo de judicialização, o Poder Judiciário tem exercido importante papel na realização dos direitos fundamentais garantindo o acesso aos cidadãos as prestações necessárias e a adjudicação aos bens essenciais à fruição dos seus respectivos direitos.

Todavia, os excessos do ativismo judicial têm gerado preocupações uma vez que a concretização dos direitos sociais no âmbito do controle judicial ignora que no sistema representativo o campo adequado para a conveniência da decisão política é a deliberação pública e o controle social respectivo.

Em tal vértice, o arcabouço normativo tributário de arrecadação e vinculação das contribuições previdenciárias insere-se no sistema de garantia e proteção dos direitos sociais que encontra na Seguridade Social o campo adequado para a concessão das prestações necessárias à garantia do mínimo existencial.

Os limites do ativismo judicial realizado com fins de promoção do mínimo existencial diante do papel exercido pela seguridade social no fornecimento da adjudicação de bens e oferecimento de serviços necessários à fruição dos direitos sociais é o tema posto em debate neste trabalho.

Analisa-se em que medida, uma vez que a seguridade social garante a adjudicação das prestações necessárias para a satisfação dos direitos sociais, o Poder Judiciário apenas pode atuar de forma excepcional, tão somente quando verificada a real incapacidade de 
oferecimento pela Administração Pública e a efetiva necessidade pelo administrado.

Para tanto de início analisa-se os direitos sociais de forma a determinar o grau de sua exigibilidade. Após, verifica-se o papel do ativismo judicial na garantia da concretização de tais direitos fundamentais pela via jurisdicional. Por fim, confronta-se o papel da Seguridade Social na realização do mínimo existencial de forma a delimitar limites à atuação do Poder Judiciário de ordem técnica, financeira e administrativa.

\section{OS DIREITOS SOCIAIS E A EXIGIBILIDADE}

$\mathrm{Na}$ nossa experiência constitucional antes restrita a Constituições Garantistas que tutelavam as liberdades formais como repositórios de promessas vagas (BARROSO, 2003), os direitos sociais remetidos à esfera programática de meras linhas diretoras aos poderes públicos e tidos como dotadas de eficácia limitada ${ }^{1}$, passam a gozar de exeqüibilidade plena, permitindo sejam os bens e interesses que tutelam exigíveis perante o Estado $^{2}$.

Ascende com o declínio do Estado Providência e tendo por fundamento as declarações e pactos internacionais, a tese da indivisibilidade dos direitos humanos ${ }^{3}$. Segundo a construção, os direitos sociais se identificam como uma segunda geração ou ciclo dos direitos fundamentais, porém, sua exigibilidade se sujeita a certos parâmetros.

Com alicerce no Pacto Internacional dos Direitos Econômicos, Sociais e Culturais, esta doutrina distingue os direitos civis e políticos dotados de auto-aplicabilidade e, portanto, assegurados de forma imediata pelo Estado, dos direitos sociais que se sujeitam a realização progressiva pelos poderes públicos até o máximo dos recursos disponíveis ${ }^{4}$.

Isto decorria da impossibilidade de aplicabilidade integral dos direitos sociais em um curto período de tempo, diante de sua demanda por recursos econômicos em um contexto de escassez e escolhas dramáticas, que imporiam a adoção de medidas econômicas e técnicas, isoladas ou em conjunto pelo Estado em cooperação internacional de forma graduada. 
Neste ponto, a tese sustentada encontra alguns impasses, em especial, a restrição da eficácia dos direitos sociais, vistos como fundamentais, à intermediação dos poderes públicos. Admitir que, por exemplo, a promoção da medicina de urgência se condicione a agenda de governo é retornar ao período de pouca virtualidade jurídica dos direitos sociais.

Em razão disto, é recorrente a criação de balizas pelos juristas, que buscam definir uma posição entre os extremos apresentados - a exigibilidade imediata de todos direitos sociais e a dependência para sua concretização dos poderes constituídos - capaz de delimitar um núcleo mínimo exigível de prestações positivas dos direitos sociais.

Certa perspectiva, parte da premissa de que as normas constitucionais conformam de modo distinto os postulados que orientam a ordem econômica e social. Enquanto algumas disposições possuem a estrutura lógico-normativa de regras definindo direitos outras ordenam interesses com um caráter prospectivo ${ }^{5}$.

As normas programáticas indicam os fins sociais almejados, através de proposições diretivas imediatamente observáveis e projeções de comportamento de efetivação progressiva inserto no universo das possibilidades do Estado e da Sociedade. Embora não gerem direitos a prestações para os seus titulares, produzem consequências desde o início de sua vigência.

Em outra vertente, as normas constitucionais definidoras de direito veiculam bens e interesses sociais conceitualmente qualificáveis como direitos subjetivos, que são pronta e diretamente exigíveis dos poderes públicos. Estas regras, todavia, produziriam efeitos de ordens variadas investindo os jurisdicionados em posições jurídicas diferentes.

Dadas normas permitiriam que situações fossem prontamente desfrutáveis dependentes apenas da abstenção pelos os poderes públicos. Outras ensejariam a prática de determinadas prestações positivas pelo Estado. Por fim, certas contemplariam interesses que dependeriam da edição de norma infraconstitucional integradora ${ }^{6}$.

Note, porém, que todos os direitos para alcançar a sua efetividade dependem da prática de prestações positivas e 
negativas pelos poderes públicos. Este dever estatal na concretização dos direitos sociais pode ser disposto em níveis de obrigações estatais, identificadas desde o dever de respeitar e proteger, até assegurar e promover o acesso aos bens sociais. (ABRAMOVICH; COURTIS, 2003).

Outra tese busca a afirmação dos direitos sociais através da redefinição de sua jusfundamentalidade ${ }^{7}$. Com esteio em algumas teorias do direito e da filosofia política, os direitos sociais seriam fundamentais apenas quanto o seu núcleo essencial, ou seja, as condições mínimas indispensáveis para uma existência humana digna ${ }^{8}$.

Por conseqüência, na realização dos direitos sociais são definidas duas medidas que confluem para o equilíbrio entre liberdade e justiça, resultantes da impossibilidade de se promover os bens e interesses sociais em toda sua extensão e a necessidade de garantir a sua efetividade ao menos em profundidade na sua dimensão mínima.

Um vetor refere-se ao dever de maximização pelo Estado do conteúdo dos direitos sociais que integra o mínimo existencial, impondo a sua realização na dimensão máxima através da promoção de prestações negativas e positivas, insuscetíveis de restrições pelos poderes públicos e plenamente garantidos pela jurisdição.

Outro diz respeito ao dever de otimização no que excede este conjunto básico realizável também por políticas públicas, mas exigíveis originariamente por via do exercício da cidadania reivindicatória, e de forma subsidiária pelo Poder Judiciário, observadas as reservas de distintas ordens a que estão sujeitos.

Observa-se, portanto, uma tendência progressiva iniciada com a superação do caráter programático dos direitos sociais e o reconhecimento de sua dimensão subjetiva, da delimitação de sua exigibilidade perante o Poder Judiciário, de forma a permitir a sua concretização no mundo dos fatos, dentro dos limites e possibilidades da Constituição.

Neste sentido, as últimas teorias, tidas de forma correlata, viabilizam um ponto ideal entre a inegável impossibilidade de se declarar a jusfundamentalidade de todas as regras que 
veiculam bens e interesses sociais e a indiscutível inviabilidade de tornar-se exigível todas as prestações decorrentes dos direitos sociais $^{9-10}$.

Adstringir a análise da aplicabilidade dos direitos sociais à delimitação do seu núcleo essencial permite dotar de exigibilidade direta e imediata suas normas apenas quanto a um conteúdo que se identifique com as condições mínimas para uma existência humana digna e pressupostos iniciais para a participação democrática ${ }^{11}$.

Naquilo que exorbitar este microcosmo, os direitos sociais possuem exigibilidade mediata condicionada sua concretização à intermediação pelos poderes públicos, através das escolhas dramáticas realizadas, nos limites de sua esfera de conformação ou discricionariedade, em um contexto de multiplicidade de atribuições e escassez de recursos econômicos.

Garante-se, portanto, por esta via, a promoção dos bens e interesses sociais em vista a legitimidade democrática, preservando um núcleo essencial - que corresponde às condições para o exercício da cidadania - e o espaço dos poderes públicos na otimização progressiva destes direitos, em uma proposta eficaz na tensão entre constitucionalismo e democracia.

Neste sentido, destaca-se o papel do Poder Judiciário na concretização dos direitos sociais através da concessão mediante provimento judicial do conteúdo necessário a garantia do exercício da cidadania, quando não garantido pelas searas democráticas, sob pena de excesso no ativismo judicial.

$\mathrm{O}$ tema será tratado a seguir.

\section{O ATIVISMO JUDICIAL E OS DIREITOS SOCIAIS}

Com a Constituição Federal de 1988 houve processo de ampla disciplina de matérias políticas e sociais, que antes sujeitas ao campo da legislação que passam a se submeter apenas a regulamentação pelas normas infraconstitucionais, garantindo maior segurança e estabilidade jurídica em face das ingerências fugazes dos poderes constituídos. (VIEIRA, 2008).

Com a previsão exaustiva dos bens e interesses sociais na lei fundamental e a respectiva subtração das questões da vida política 
e social do alcance do legislador, essas passaram a encontrar fundamentos imediatos nas normas constitucionais sujeitando-se ao controle de adequabilidade dos atos legislativos e administrativos com a lei fundamental.

Esses novos paradigmas importam um novo papel das cortes judiciais na promoção dos valores constitucionais, que aliado ao acréscimo da demanda social por justiça e a recuperação das garantias institucionais, resulta na ascensão político-institucional do Poder Judiciário e na expressiva judicialização das questões políticas e sociais.

No vértice da ascensão político-institucional do Poder Judiciário, a recuperação das liberdades democráticas e das garantias institucionais dos membros da magistratura com a redemocratização brasileira, permitiram um campo de independência e imparcialidade na aplicação do direito vigente e na interpretação das normas constitucionais. (BARROSO, 2007).

No campo da judicialização, as questões políticas e sociais que aprioristicamente estariam sujeitas ao campo do processo político majoritário e exteriorizadas na conformação legislativa e discricionariedade administrativa passam a ser decididas pelo Poder Judiciário na preservação da supremacia da Constituição e dos bens e valores por ela veiculados.

É aferida através da atribuição aos órgãos de controle de constitucionalidade da resolução de conflitos de competência relativo ao exercício do poder estatal, do controle do exercício da conformação legislativa e discricionariedade administrativa pelo Poder Judiciário e do emprego das normas constitucionais na argumentação dos atores políticos.

Como efeito, observa-se um crescente exercício das ações abstratas pelos atores políticos e sociais, que amplia a influência da Constituição sobre as relações políticas, bem como, a atuação do Supremo Tribunal Federal (STF) na decisão de matérias essenciais para a sociedade.

Em um cenário de judicialização das questões políticas e sociais, bem como, de déficit de legitimidade e representatividade das instâncias democráticas, observa-se o exercício de um papel ativo das cortes judiciais na concretização dos valores e fins veiculados pela constituição, usualmente designado de ativismo judicial. 
O ativismo judicial corresponde a uma atuação intensa e ativa do Poder Judiciário em questões políticas e sociais que caberiam precipuamente aos demais poderes, de forma a garantir a concretização dos valores e fins veiculados pelas normas constitucionais e preservar a supremacia axiológica e formal da Constituição ${ }^{12}$.

Sua origem é apontada no início do século XX com as decisões da Suprema Corte dos Estados Unidos ${ }^{13}$ e a partir da década de 1950 do Tribunal Constitucional Alemão e Italiano ${ }^{14}$ na tutela dos direitos fundamentais, se notabilizando no Brasil nos últimos anos com decisões sobre importantes questões políticas e sociais pelo $\mathrm{STF}^{15}$.

Envolve a aplicação direta e imediata da Constituição em situações não expressamente contempladas no texto constitucional, diante de omissão ou violação por disciplina normativa pelo legislador ou ato concreto do administrador, com vistas à garantia de proteção ou concretização dos valores e fins constitucionais ${ }^{16}$.

Abrange a invalidação de atos normativos emanados do Poder Legislativo ou Administrativo de constitucionalidade discutível, ou seja, com adoção de critérios menos rígidos do que aqueles onde inexiste patente e ostensiva violação da Constituição, com vista à preservação da hierarquia das normas constitucionais ${ }^{17}$.

Por fim, compreende a imposição de condutas ou de abstenções ao Poder Público capazes de impedir violação ou garantir a concretização de direitos e fins constitucionais, em especial, mediante o controle judicial sobre os programas de políticas públicas de forma a assegurar o acesso a prestações a bens e serviços essenciais ${ }^{18}$.

No Brasil o ativismo judicial está diretamente relacionado com a crise de legitimidade e representatividade democrática, que gera um descolamento entre os órgãos representativos e a sociedade, e a incapacidade ou desinteresse em atender as demandas sociais, produzindo um deslocamento do exercício da cidadania para o âmbito do Poder Judiciário.

A redução da deliberação política ao processo eletivo (BARCELLOS, 2008), a histórica e perniciosa influência econômica dos agentes políticos sobre o eleitor (FAORO, 2000) e a captação dos agentes políticos por grupos de interesse (MANCUSO, 2007), conduz a um distanciamento entre representante e representado, pro- 
movendo estreitamento do debate político que se transfere para os órgãos judiciários.

O desinteresse dos atores políticos em atender questões de interesse social onde há um desacordo moral razoável na comunidade, de forma a evitar os desgastes promovidos pelo debate e os riscos da responsabilização política nas eleições, torna o Poder Judiciário uma instância decisória política de questões polêmicas.

O processo de hipertrofia legislativa com a explosão de legislação infraconstitucional e regulamentação infralegal, bem como, a atecnicidade da produção legislativa com a criação de conceitos jurídicos indeterminados desencadeiam a ampliação dos conflitos na sociedade e litigiosidade, bem como, o potencial criativo e margem de discricionariedade do Judiciário ${ }^{19}$.

As omissões legislativas na regulamentação de preceitos impostas pela Constituição que impede o exercício dos direitos pelos representados, aliado a instituição de mecanismo próprio de controle de constitucionalidade pela via concentrada e a utilização de ação constitucional na via incidental, impõem a intervenção judicial na decisão política.

Por um lado é inegável que o cenário brasileiro ainda é marcado por estrutura deficitária, desperdício de recursos, desvios de verbas e ineficiência dos agentes estatais, que resultam na precariedade dos serviços prestados na promoção dos direitos fundamentais e tornam constante a necessidade de controle de políticas públicas. (APPIO, 2008).

Porém, isto não significa um controle judicial ilimitado, que permita ao juiz sob o manto da realização dos valores e bens constitucionais, promover o exercício de preferências políticas através de programas públicos, em desconsideração à falta de legitimidade, à nítida limitação técnica e às distorções que podem gerar no sistema globalmente considerado.

Embora a Constituição veicule as opções fundamentais da sociedade, não deve ser utilizada como instrumento de modelagem de todos os espaços sociais, ignorando a área livre de conformação utilizada pelos agentes políticos para conduzir com a participação dos atores sociais as deliberações públicas na busca pela solução das demandas contemporâneas. 
Neste sentido, inconteste a inserção da seguridade social dentre as políticas públicas estatais que buscam garantir a concretização dos direitos sociais e, portanto, a esfera adequada para implementação das prestações necessárias a garantir o mínimo existencial configurando um limite à atuação do Poder Judiciário.

$\mathrm{O}$ tema será tratado a seguir.

\section{A SEGURIDADE SOCIAL E O MÍNIMO EXISTENCIAL}

A seguridade social enquanto conjunto integrado de ações destinadas a assegurar os direitos relativos à saúde e assistência e previdência social, é financiada de forma mista pela adoção do modelo assistencial - custeio direto por meio do orçamento fiscal, mediante a cobrança de impostos em geral - e contributivo - pagamento de contribuições sociais impostas aos agentes de processo produtivo. (BRASIL, 1988).

Através da instituição de um sistema misto de custeio, baseado no equilíbrio entre as dotações orçamentárias, busca-se garantir uma independência e necessária estabilidade financeira dos órgãos previdenciários, capaz de permitir a consecução de suas finalidades institucionais exteriorizada na promoção de planos e programas de ações que concretizem aqueles direitos sociais de forma universal. (BOTELHO, 2002).

Neste tocante, diversificando as fontes de financiamento da seguridade social foram instituídas pela Constituição contribuições sociais devidas: ao empregador, à empresa e à entidade a ele equiparadas; do trabalhador e demais segurados da previdência social, excluída sua incidência sobre aposentadoria e pensão do regime geral de previdência social; da receita de concursos de prognósticos; e do importador de bens ou serviços do exterior.

Essas contribuições sociais têm como característica principal ou elemento essencial a afetação do produto de sua arrecadação às despesas genéricas com a seguridade social, que fundada na ideia da solidariedade ao grupo apresenta dúplice efeito: impede destinação distinta daquela finalidade constitucional ${ }^{20}$ e enseja o direito subjetivo dos seus contribuintes de sua aplicação nos gastos efetivos ou devolução das contribuições pagas. (BEREIJO, 1976).

Todavia, embora o desenho institucional delineado pela Constituição de 1988 para a Seguridade Social com financiamento pela 
afetação das contribuições sociais stricto sensu busque trazer maior efetividade à implementação daqueles direitos sociais universais, sua concretização encontra óbices na regulamentação legislativa, implementação de políticas públicas e, especialmente, na aplicação dos recursos.

No âmbito da regulamentação legislativa, a existência de um complexo de leis distintas que regulamentam cada um dos setores sociais - a saúde, assistência social e previdência - editadas em conjunturas políticas e econômicas distintas e sem coordenação dos atores envolvidos com essas políticas, torna difícil a articulação de um sistema eficaz de proteção social. (TEIXEIRA, 2007).

No que se refere às políticas públicas, as trajetórias institucionais e técnicas distintas desses setores produziram a desarticulação entre saúde, assistência social e previdência, obstaculizando o desenvolvimento de promoção de ações intersetoriais, resultando na fragmentação dos programas e políticas públicas da Seguridade Social, conduzindo a poucos avanços práticos na concretização desses direitos sociais. (FLEURY, [20--?]).

Por fim, no que tange à aplicação de recursos, os reiterados contingenciamentos das verbas destinadas a políticas sociais, sua utilização como instrumentos de ajuste fiscal do governo e o seu desvio para financiamento de atividades alheias à Seguridade Social dificultam a implementação de políticas capazes de gerar a fruição efetiva daqueles direitos sociais. (ARAÚJO, 2005).

A parafiscalidade insere-se no sistema de proteção social organizado pelo Estado, enquanto financiamento fiscal dos planos de ação estatal voltados ao patrocínio dos direitos sociais e condições mínimas de vida, que baseado no princípio da solidariedade, impede a repartição do encargo financeiro decorrente de benefícios auferíveis apenas por certo grupo para toda a sociedade ${ }^{21}$.

O mínimo existencial, que envolve as condições fundamentais para uma vida com dignidade ${ }^{22}$, mas envolve pressupostos essenciais para o funcionamento adequado do próprio sistema jurídico-democrático que constituem matriz irredutível, indisponível e insuscetível de restrição pelos poderes públicos e controlados pela jurisdição.

Assim, abrange a adjudicação pelos poderes públicos das prestações materiais necessárias à fruição do direito à liberdade e à 
igualdade, permitindo que o indivíduo possa exercer efetivamente sua autonomia na esfera privada e pública ${ }^{23}$ e tenha possibilidade de participar e cooperar de forma igualitária no processo político democrático ${ }^{24}$.

Por efeito, a rigor cabe à articulação pelos poderes públicos dos programas de ação governamental inseridos dentro da Seguridade Social que coordenem os meios colocados à disposição, harmonizando as atividades estatais e privadas, para a realização destes objetivos socialmente relevantes e politicamente determinados. (BUCCI, 2002).

Por conseguinte, a Administração Pública, in casu, exerce um papel relevante na elaboração, execução e implementação das políticas públicas da Seguridade Social, permitindo na sua coordenação com os poderes orgânicos e a articulação dos elementos complexos do sistema - estrutura, recursos e pessoas - um maior grau de efetividade da ação governamental.

Inclui no âmbito da criação e execução orçamentária ao determinar as prioridades e a destinação dos recursos públicos na gestão econômica e financeira do Estado, inclusive, firmando quais prestações serão realizadas, através de escolhas difíceis em um contexto em que haveria escassez de recurso e de multiplicidade de demandas.

Embora entenda-se que o cerne da questão não é a indisponibilidade financeira ${ }^{25}$, mas de falta de planejamento e execução orçamentária ${ }^{26}$ inevitável que não cabe ao Poder Judiciário emitir corriqueiramente decisões de alocação ou sequestro de verbas necessárias à prestações de concretização aos direitos fundamentais ignorando o planejamento estatal subjacente.

Em especial, por faltarem conhecimentos de ordem técnico-científicos necessários à ordenação das políticas públicas, que possui a Seguridade Social. Dispõe a Administração Pública de um conjunto de informações referentes a demandas, métodos e recursos hábeis a imprimir uma gestão profissional na persecução do interesse público. (MOREIRA NETO, 2001).

Cabe aos poderes públicos a organização da estrutura, bens e pessoas colocados à disposição, de forma a imprimir na gestão pública, a otimização na promoção dos direitos sociais, de forma que quando atua na sua microjustiça desencadeia distorções no sistema 
globalmente considerado que inviabilizam a eficiência da atuação estatal $^{27}$

Isto porque, ainda sob um sistema processual centrado nas ações individuais, há tratamento atomizado do conflito e limitação a participação de atores imediatamente envolvidos (SARMENTO, [20--?]), o processo judicial se torna campo inadequado com restritos atores envolvidos para interferir sobre as políticas públicas da Seguridade Social.

Claro que não se ignora os limites da Seguridade Social ao afiançar as prestações necessárias a garantia do mínimo existencial e, portanto, que os poderes constituídos não possam dispor livremente dos direitos sociais gerando o esvaziamento da eficácia de suas normas a título de proteção da democracia.

No Estado Brasileiro marcado pela miséria e desigualdade social, capaz de excluir grande parcela da sociedade das condições mínimas para uma existência digna e a participação efetiva no processo democrático, a atuação do Poder Judiciário na concretização das políticas públicas permite garantir o núcleo essencial dos direitos sociais.

Porém, é necessário que a atuação do Poder Judiciário em proteção ao princípio democrático, bem como, na garantia da própria efetividade das políticas públicas apenas ocorra quando o Sistema de Seguridade Social se demonstre incapaz de atender efetivamente o cidadão que almeja a prestação requerida.

\section{CONCLUSÃO}

Com o processo de redemocratização e a promulgação de uma Constituição Cidadã com o compromisso de promover a superação das desigualdades sociais e econômica, além da ampla consagração dos direitos sociais, houve um movimento de busca da garantia da eficácia e implementação dos referidos direitos fundamentais.

Sob tal viés, o Poder Judiciário exerce importante movimento no reconhecimento da exigibilidade perante os poderes públicos dos direitos sociais e na determinação de realização de políticas públicas capaz de garantir a sua concretização, em especial, no que se refere à proteção do mínimo existencial. 
Todavia, em um Estado Democrático de Direito, além da proteção dos preceitos constitucionais, deve haver a tutela do princípio democrático com o reconhecimento que a seara adequada para exercício da cidadania e a tomada de decisão política é eminentemente nos órgãos representativos, realçando o papel do Poder Executivo na realização dos direitos sociais.

Neste sentido, a atuação do Poder Judiciário na garantia do mínimo existencial, além da observância de pressupostos - as prestações necessárias à uma vida digna e exercício da cidadania - deve ocorrer somente quando demonstrar a real incapacidade de atendimento e a efetividade necessidade da prestação.

Em que pese as dificuldades que a Seguridade Social enfrenta em um país com grandes demandas sociais e problemas econômicos, o sistema possui políticas públicas articuladas para a garantia das prestações necessárias à concretização dos direitos sociais auxiliando na proteção do mínimo existencial.

Por efeito, qualquer atuação desarticulada do Poder Judiciário ao invés de contribuir com a concretização dos direitos sociais, pode causar distorções no sistema gerando efeitos perniciosos ao macrosistema de proteção social o que demanda, portanto, limites no ativismo judicial como forma de garantir o mínimo existencial.

\section{REFERÊNCIAS}

ABRAMOVICH, V.; COURTIS, C. Apuntes sobre la exigibilidad judicial de los derechos sociales. In SARLET, I. W. (Org). Direitos fundamentais sociais: estudos de direito constitucional, internacional e comparado. Rio de Janeiro: Renovar, 2003.

APPIO, E. Controle Judicial das Políticas Públicas no Brasil. Curitiba: Juruá, 2008.

ARAÚJO, É. A. Análise das Contribuições Sociais no Brasil. Brasília, DF: CEPAL, 2005.

ARLET, I. W. O direito fundamental à moradia na constituição, algumas anotações a respeito de seu contexto, conteúdo e possível eficácia. In: MELLO, C. de A.; TORRES, R. L. (Dir.). Arquivos de direitos humanos. Rio de Janeiro: Renovar, 2002. n. 4, p. 137-191.

BARCELLOS, A. P. de. Papéis do direito constitucional no fomento do controle social democrático: algumas propostas sobre o tema da 
informação. RDE: Revista de Direito do Estado, Rio de Janeiro, v. 3, n. 12, p. 77-105, out./dez. 2008.

BARROSO, L. R. A Americanização do direito constitucional e seus paradoxos. In: _. Temas de direito constitucional. Rio de Janeiro: Renovar, 2009. T. iv.

BARROSO, L. R. A reconstrução democrática do direito público no Brasil: livro comemorativo dos 25 anos de magistério do professor Luís Roberto Barroso. Rio de Janeiro, Renovar: 2007.

. Da falta de efetividade à judicialização excessiva: direito à saúde, fornecimento gratuito de medicamentos e parâmetros para atuação judicial. Revista Jurídica UNIJUS, Uberaba, v. 11, n. 15, p. 13-38, nov. 2008.

Diferentes mais iguais: o reconhecimento jurídico das relações homoafetivas no Brasil. Boletim Científico da Escola Superior do Ministério Público da União, Brasília, DF, v. 6, n. 22/23, p. 117-163, jan./jun. 2007.

. Interpretação e aplicação da Constituição. 6. ed. Rio de Janeiro: Saraiva, 2006.

. O direito constitucional e a efetividade de suas normas. 7 ed. Rio de Janeiro: Renovar, 2003.

BEREIJO, A. R. Introducción al estudio del derecho financiero: un ensayo sobre los fundamentos teóricos del Derecho Financiero. Madrid: Instituto de Estudios Fiscales, 1976.

BOBBIO, N. A era dos direitos. 9. ed. Rio de Janeiro: Elsevier, 2004. BONAVIDES, P. Curso de Direito Constitucional. 13. ed. São Paulo: Malheiros, 2003.

BOTELHO, W. As contribuições sociais no direito brasileiro. Rio de Janeiro: Forense, 2002.

BRASIL. República Federativa do Brasil. Constituição Federal de 05 de Outubro de 1988. Brasília, DF, 1988.

BUCCI, M. P. D. Direito administrativo e políticas públicas. São Paulo: Saraiva, 2002.

CALMON, S. Curso de direito tributário brasileiro. 9. ed. rev. e atual. Rio de Janeiro: Forense, 2006.

CAMPILONGO, C. F. O Direito na sociedade complexa. São Paulo: Max Limonad, 2000. 
CANOTILHO, J. J. G. Direito constitucional e teoria da Constituição. 7. ed. Coimbra: Almedina, 2003.

FAORO, R. Os donos do poder. 15. ed. São Paulo: Editora Globo, 2000.

FLEURY, S. A seguridade social inconclusa. Rio de Janeiro: FGV, [20--?]. Disponível em: <http://app.ebape.fgv.br/comum/arq/ Seguridade.pdf $>$. Acesso em: 5 mar. 2016.

GALDINO, F. O custo dos direitos. In: TORRES, R. L. Legitimação dos direitos humanos. Rio de Janeiro: Renovar, 2002.

GALLACCI, F. B. O STF e as Cláusulas Pétreas: o ônus argumentativo em prol da governabilidade? São Paulo: SBDP, 2011.

IBRAHIM, F. Z. A parafiscalidade: ascensão e queda das contribuições sociais. Revista Brasileira de Direito Previdenciário, [S. 1.], n. 1, fev./mar. 2011.

MANCUSO, W. P. O Lobby da indústria no Congresso Nacional. São Paulo: EDUSP, 2007.

MELLO, C. de A. O $\S 2^{\circ}$ do artigo $5^{\circ}$ da Constituição Federal. In: TORRES, R. L. (Org). Teoria dos Direitos Fundamentais. Rio de Janeiro: Renovar, 2001.

MIRANDA, J. Manual de Direito Constitucional: Tomo IV - Direitos Fundamentais. 2. ed. Coimbra: Almedina, 1998.

MOREIRA NETO, D. de F. Mutações de Direito Administrativo. 2. ed. Rio de Janeiro: Renovar, 2001.

MOURA, E. A. da C. Do controle jurídico ao controle social: parâmetros a efetividade dos direitos sociais. Revista de Direito Constitucional e Internacional, São Paulo, ano 19, n. 77, out./dez. 2011.

PIOSEVAN, F. Direitos humanos e o direito constitucional internacional. 3. ed. atual. São Paulo: Max Limonad, 1997.

SARLET, I. W. A eficácia dos direitos fundamentais. Porto Alegre: Livraria do Advogado Editora, 2004.

SARMENTO, D. A proteção judicial dos direitos sociais: alguns parâmetros ético-jurídicos. [S. 1.: s. n.], [20--?].

SILVA, J. A. da. Aplicabilidade das Normas Constitucionais. 7 ed. São Paulo: Malheiros, 2008. 
SIQUEIRA, V. H. P. A solidariedade do grupo e as contribuições sociais. Revista de Direito da Procuradoria Geral, Rio de Janeiro, $\mathrm{n}$. 61, p. 358-366, 2006.

TEIXEIRA, S. M. Políticas sociais no Brasil: a histórica (e atual) relação entre o "público" e o "privado" no sistema brasileiro de proteção social. Sociedade em Debate, Pelotas, v. 13, n. 2, p. 45-64, jul./dez. 2007.

TORRES, R. L. O direito ao mínimo existencial. Rio de Janeiro: Renovar, 2009.

. O direito ao mínimo existencial. Rio de Janeiro: Renovar, 2009. Cap. II, p. 53-81.

VALLE, V. R. L. do. Ativismo jurisdicional e o Supremo Tribunal Federal. São Paulo: Juruá, 2009.

VAZ, A. R. A cláusula da reserva do financeiramente possível como instrumento de efetivação planejada dos direitos humanos, econômicos, sociais e culturais. Revista de Direito Constitucional e Internacional, São Paulo, ano 17, n. 66, p. 9-38, jan./mar, 2009

VIEIRA, O. V. Supremocracia. Revista de Direito GV, São Paulo, v. 4, n. 2, p. 441-464, jul./dez. 2008.

\section{NOTAS:}

1 A aplicabilidade restrita das normas de natureza programática decorreria da fluidez de suas disposições e da inexistência de instrumentos jurídico-processuais capazes de garantir sua concretização. (BONAVIDES, 2003). Compreendendo que as relações econômico-sociais são disciplinadas apenas por normas programáticas, vide Silva (2008).

2 As normas constitucionais tenham caráter imediato ou prospectivo como regras de conduta emanadas do Estado são dotadas de eficácia jurídica. Assim, incidem e regem as situações de vida produzindo os seus efeitos próprios, e, diante da sua inobservância espontânea deflagram mecanismos de aplicação coativa. (BARROSO, 2006).

3 Dentre os adeptos desta tese, estão: Bobbio (2004), Miranda (1998), Piovesan (1997) e Mello (2001)

4 Artigo $2^{\circ} \S 1^{\circ}$ do Pacto dos Direitos Econômicos, Sociais e Culturais. Embora a partir desta concepção extraída do Pacto as normas veiculadoras dos direitos sociais tenham natureza essencialmente programática, segundo a autora, isto não impede a sua exigibilidade perante o Poder Judiciário e não desvincula os demais poderes públicos de sua séria e responsável observância. (PIOVESAN, 1997).

5 Desta forma inexistira um modo de normatização uniforme na consagração dos direitos sociais pela Constituição, derivada da opção do Constituinte pela disposição em uma estrutura jurídica heterogênea, gerando normas com distintos graus de exigibilidade. Sobre o tema vide Barroso (2003, 2006) e Sarlet (2004). 
${ }^{6}$ É o que ocorre, segundo o autor, respectivamente com: o direito de greve (artigo $9^{\circ}$ ), que depende da abstenção do Estado de reprimir e punir o exercício pelos seus titulares; o direito à proteção da saúde (artigo 196) que requerer a definição de políticas sociais e econômicas voltadas a sua realização; e o direito à proteção em face da automação na forma da lei (artigo $7^{\circ}$ inciso XXVII) que depende da regulamentação pelo legislador ordinário.

7 Não tem o presente trabalho, por objetivo, se aprofundar sobre a questão da jusfundamentalidade dos direitos sociais, ainda não pacífica na doutrina brasileira. Busca apenas apresentar essa vertente, que traz um novo desenho da essencialidade às discussões da exigibilidade dos direitos sociais. Como principal adepto desta tese, vide Torres (2009) em especial p. 53-81.

8 Este direito que coincide em parte com o núcleo duro dos direitos sociais possui designações distintas nas várias ordens jurídicas. A doutrina alemã refere-se ao mínimo existencial Existenzminimum. A jurisprudência norte-americana titula como proteção mínima minimal protection. A legislação brasileira prefere adotar a expressão, mínimos sociais, acolhida pela Lei $\mathrm{n}^{\circ}$ 8.742, de 7 de dezembro de 1993.

9 É o que ocorre com o artigo 193 ao estabelecer que a Ordem Social tem como base o primado do trabalho e como objetivo o bem-estar e a justiça social, veiculando os bens e interesses supra como princípios e diretivas de atuação para os poderes públicos e não direitos que investem os seus titulares com um poder de ação. Neste sentido, também ver Barroso (2003). Sobre as possibilidades de conformação jurídica dos direitos sociais, ver Canotilho (2003).

${ }^{10}$ Assim, por exemplo, o direito à moradia não investe todos no poder de exigir prontamente acesso a habitação pelo Estado. Dentre o universo de prestações, como a habitação para as pessoas de classe média, apenas algumas são exigíveis, enquanto necessárias para garantir as condições essenciais para uma existência humana digna, como a garantia de moradia aos indigentes e às pessoas que não tem teto. Neste sentido ver Torres (2009).

${ }^{11}$ Como ilustração, no que tange ao direito de educação, são prestações passíveis de exigibilidade perante o Poder Judiciário, aquelas referentes à educação fundamental e o ensino médio, essenciais como condições iniciais para o exercício das liberdades, em especial, de ação, expressão e de associação, permitindo que o indivíduo possa buscar um projeto razoável para a sua vida e seja capaz de participar da deliberação sobre os bens e interesses almejados para a vida em sociedade.

${ }^{12}$ Como visto, não sendo a judicialização uma opção política do Poder Judiciário, mas uma decorrência do desenho institucional vigente, uma vez provocados em razão do princípio da inafastabilidade da tutela jurisdicional cabe aos juízes e tribunais se manifestarem, todavia, o modo como venham a exercer essa competência é que importará em um ativismo judicial - na concretização dos valores e fins constitucionais em atenção a supremacia axiológica da constituição - ou em uma autocontenção judicial - na preservação do ato legislativo ou administrativo em atenção ao princípio democrático, razão pelo qual, não se confunde judicialização das questões políticas e sociais com ativismo judicial.

${ }^{13}$ Inicialmente o ativismo judicial foi utilizado de forma conservadora permitindo a legitimidade para a segregação racial (Dred Scott vs. Sanford em 1857) e invalidação e leis sociais (Lockner v. New York em 1905), porém, no período de 1953 e 1969 sob a presidência de Earl Warren oram tomadas as decisões progressistas em matéria de direitos fundamentais, como em relação a segregação racial nas escolas públicas (Brown vs. Board 
SEGURIDADE SOCIAL, MÍNIMO EXISTENCIAL E ATIVISMO JUDICIAL

of Education em 1954), a incriminação do uso de pílulas anticoncepcionais (Griswold vs. Connecticut em 1965) entre outras. Sobre o tema ver Barroso (2009).

${ }^{14} \mathrm{Na}$ Alemanha, o Tribunal Constitucional fixou que a lei fundamental não era ordem neutra de valores, mas que consagrava uma ordem objetiva instrumental à garantia dos direitos fundamentais (BVerfGE7, 198, 205). Porém, assim como na Itália, tentou suavizar os impactos políticos da sua decisão, como, por exemplo, advertindo sobre as suas omissões para a sua correção ou advertindo sobre uma revogação em caso de não atuação legislativa retificadora. Sobre o tema, ver Valle (2009).

${ }^{15}$ A título exemplificativo, podemos citar, algumas decisões do Supremo Tribunal Federal que denotam um ativismo judicial: a fidelidade partidária, a vedação do nepotismo, a verticalização as coligações partidárias e cláusula de barreira, o direito a greve no serviço público dentre outros.

${ }^{16}$ Como, por exemplo, no caso das uniões homoafetivas (ADPF 132) onde inexiste regra constitucional expressa que tutele as relações ou prescreva a aplicação do regime de união estável, bem como, não há vedação da norma do artigo $226 \$ 3^{\circ}$ que ao tratar de homem e mulher buscou a superação da desigualdade na relação de casamento e não impedir a aplicação do regime às uniões homoafetivas. Neste sentido, o STF com fundamento na dignidade da pessoa humana aplicou o regime das uniões estáveis a essa nova modalidade de família. Sobre o tema, ver Barroso (2007).

${ }^{17}$ Como, por exemplo, no caso da verticalização (ADIn 3685) onde o artigo $2^{\circ}$ da Emenda Constitucional 52 de 8 de março de 2006 alterava o artigo $17 \S 1^{\circ}$ da Constituição da República, fixando data para alteração, em violação ao princípio da anterioridade anual da lei eleitoral. (BRASIL, 1988, art. 16). O Supremo Tribunal Federal para proteger a norma constitucional, que embora não tivesse uma violação frontal perderia sua eficácia, declarou inconstitucional a emenda constitucional dando a norma do artigo 16 o status de cláusula pétrea embora não se enquadre ao rol de cláusulas elencadas na Constituição. Sobre este tema consulte-se Gallacci (2011).

18 Como, por exemplo, as ações judiciais relativas à concretização de prestações necessárias a fruições de direitos sociais (alimentação, saúde e moradia ...) concedidas pelos órgãos do Poder Judiciário como, por exemplo, a distribuição de medicamentos e determinação de terapia. O Supremo Tribunal Federal na ADPF 45/DF se manifestou, no sentido, que não obstante a formulação e a execução das políticas públicas dependam de opções políticas a cargo daqueles que, por delegação popular, receberam investidura em mandato eletivo, cumpre reconhecer que não se revela absoluta, neste domínio, a liberdade de conformação do legislador, nem a de atuação do Poder Executivo, de modo que não podem proceder com a clara intenção de neutralizar, comprometendo-a, a eficácia dos direitos sociais, econômicos e culturais. Sobre o tema, em seus limites e possibilidades, ver Moura (2011).

${ }^{19}$ A hipertrofia do direito legislado e a produção de leis vagas reforçam e alimentam a possibilidade do direito judicial transferindo para o Poder Judiciário a decisão sobre conflitos que caberiam ser dirimidos no âmbito político. (CAMPILONGO, 2000).

${ }^{20}$ Os fins constitucionalmente pretendidos revelam uma diretriz constitucional, que não permite nem o legislador ao regulamentar a contribuição e tão pouco ao administrador ao arrecadá-las a destinar ou tredestinar o seu produto de arrecadação para finalidade diversa da prevista na Constituição. (CALMON, 2006).

${ }^{21}$ Para parte da doutrina, a solidariedade do grupo erigida à princípio de justiça fundamenta a cobrança das contribuições sociais da seguridade social em geral. (SIQUEIRA, 2006). 
Para outros autores, a solidariedade não é fundamento que informa as contribuições sociais stricto sensu, pois no subsistema da saúde e da assistência social, não há proteção irrestrita da sociedade no primeiro e cobertura assistencial independente de contribuição. (IBRAHIM, 2011).

${ }^{22}$ É o que ocorre, por exemplo, com a educação fundamental e a medicina preventiva e de urgência que correspondendo respectivamente ao núcleo essencial do direito à educação e saúde, poderiam ser exigidas pelos indivíduos que precisem perante o Poder Judiciário sem restrições. Já o ensino superior e o médio e a medicina curativa exorbitariam este conteúdo, razão pelo qual, dependeriam da progressiva realização pelos poderes públicos. (TORRES, 2009).

${ }^{23}$ Como ilustração, no que tange ao direito de educação, não envolve apenas as prestações referentes à educação fundamental, pois o ingresso nos níveis mais avançados de ensino depende da capacidade de cada um e envolve a necessária igualdade de condição, ou seja, o acesso ao Ensino Médio, permitindo que o indivíduo possa buscar um projeto razoável para a sua vida (faculdade) e seja capaz de participar da deliberação política de forma igualitária com os demais.

${ }^{24}$ A igualdade envolve, em certa medida, uma igualdade econômica e social razoável que permita que todos os indivíduos e grupos em um contexto de pluralismo tenham condições e se vejam motivados a cooperar no processo político democrático. É inverossímil sustentar que uma pessoa que não tem acesso a alimentação adequada ou a saúde curativa, bem como, um grupo hipossuficiente sem saneamento básico ou acesso a programas sociais, sejam capazes de participar do debate democrático em igual condição com os demais indivíduos e grupos.

${ }^{25}$ De fato, a questão não tem por objeto central a indisponibilidade financeira, pois uma vez que a captação de recursos públicos é realizada de forma permanente pelo Estado, há permanente possibilidade de garantia dos direitos sociais, seja através da abertura de créditos suplementares ou da previsão no exercício financeiro seguinte. O que frustra a realização dos direitos sociais é a opção política de não alocar verbas destinada às prestações relativas aquele direito, sendo o argumento da exaustação orçamentária utilizado para encobrir as escolhas trágicas, que excluíram a tutela de determinado direito. Sobre o tema, ver Galdino (2002).

${ }^{26}$ Neste sentido, não cabe, portanto, o Estado utilizar de sua própria torpeza para furtarse da obrigação de efetivar o direito social. Ao contrário, a alegação da insuficiência de recursos para a efetivação destes direitos, deve ser demonstrada por meio da indicação do planejamento, dotação orçamentária e aplicação dos recursos que torne inviável a realização do núcleo não essencial. (VAZ, 2009).

${ }^{27}$ Isto decorre da visão restrita do Poder Judiciário, que ignora o gerenciamento de recursos limitados que busca equacionar as demandas ilimitadas da sociedade, bem como, os impactos que a sua decisão pode gerar em um contexto de escassez de recursos e escolhas trágicas, promovendo uma desorganização na gestão pela Administração Pública, que passa a se dedicar ao atendimento das demandas individuais ao invés dos programas coletivos. (BARROSO, 2008). 